\title{
CES
}

COOPERATIVISMO E ECONOMÍA SOCIAL

Núm. 43 (2020-2021), páxs. 289-297

ISSN: 2660-6348

\section{APUNTAMENTOS SOBRE O LIBRO BRANCO DA ECONOMÍA SOCIAL DE CASTILLA-LA MANCHA}

\section{NOTES ON THE WHITE PAPER OF THE SOCIAL ECONOMY OF CASTILLA-LA MANCHA}

\author{
Julio Costas Comesaña*
} uvigo.gal 


\title{
RESUMO
}

Dentro da axenda de actividades programadas co gallo do nomeamento da cidade de Toledo como capital europea da economía social, a publicación do Libro Branco da Economía Social de Castilla-La Mancha foi o acontecemento con maior importancia para o sector. O Libro Branco conten unha completa e exhaustiva análise das distintas entidades que integran este sector económico e social na rexión. O estudio foi realizado por un grupo de profesores da Universidade de CastillaLa Mancha, coa colaboración de entidades do sector, seguindo a metodoloxía do CIRIEC-España, polo que reflicte unha realidade que resulta comparable coa de outros libros brancos xa publicados por outras Comunidades Autónomas, ao tempo que descubre as fortalezas e debilidades da Economía Social en Castilla-La Mancha, facendo así posíbel que as entidades e as administracións poidan adoptar a medidas adecuadas para reforzar unhas e por remedio ás outras.

Palavras chave: Libro Blanco. Economía Social. Castilla-La Mancha. España.

\begin{abstract}
Within the program of activities carried out in the context of the designation of the city of Toledo as the European capital of the social economy, the publication of the White Paper on the Social Economy of Castilla-La Mancha was the most important event. The White Book contains a complete and exhaustive analysis of the different entities that make up this socio-economic sector in this country. This study has been carried out by a group of professors from the University of CastillaLa Mancha with the collaboration of entities in the sector, following the CIRIECSpain methodology. Therefore, it reflects a reality that can be compared with that of the white books published by other Spanish countries, while discovering the strengths and weaknesses of the Social Economy in Castilla-La Mancha, thus making it possible for entities and public administrations to carry out the appropriate measures and policies to reinforce some and remedy the others.
\end{abstract}

Keyworlds: White Paper. Social Economy. Castilla-La Mancha. Spain. 
SUMÁRIO: I. CONTEXTO E METODOLOXÍA DO LIBRO BRANCO. II. RADIOGRAFÍA DA ECONOMÍA SOCIAL DE CASTILLA-LA MANCHA. III. ESTRUTURA INTERNA DO LIBRO BRANCO.

SUMMARY: I. CONTEXT AND METHODOLOGY OF THE WHITE PAPER. II. THE RADIOGRAPHY OF THE SOCIAL ECONOMY OF CASTILLA-LA MANCHA. III. INTERNAL STRUCTURE OF THE WHITE PAPER.

\section{Contexto E metodoloxía do Libro Branco}

Declaración de Luxemburgo, adoptada na Conferencia de Luxemburgo
celebrada en decembro de 2015 polos representantes de seis Gobernos da
Unión Europea, establece que a Unión debe chegar a un entendemento común sobre o alcance da economía social e respectar a súa enorme diversidade e a súa evolución histórica en tódolos Estados membros, defendendo a inclusión da economía social no proceso de modernización da estratexia do mercado único europeo. Con posterioridade a 2015, outros Estados uníronse a esta Declaración, de sorte que actualmente está integrada por 14 Estados membros da Unión. A Declaración de Luxemburgo conta cun Comité de Seguimento, tendo ostentado España a primeira presidencia no ano 2017. Durante ese ano, celebrouse en Madrid unha conferencia europea sobre economía social, titulada: "La economía social, un modelo de negocio para el futuro de la Unión Europea”, decidíndose que, polo seu impacto, Madrid tiña sido a capital europea da economía social no 2017, e que cada ano se crearía unha capital europea para a economía social. En 2018 esta capitalidade foi ostentada pola cidade de Maribor (Eslovenia), en 2019 por Estrasburgo (Francia) e en 2020 por Toledo.

Pois ben, no marco da declaración de Toledo como Capital Europea da Economía Social 2020, o Goberno de Castilla-La Mancha xunto co Concello de Toledo e o Ministerio de Traballo impulsaron diversas actividades que serviron para establecer as fortalezas e debilidades do sector da economía social nesta rexións, sendo neste contexto ou axenda de eventos que nese ano se constituíu a "Confederación de Asociaciones de Empresas de Economía Social de Castilla-La Mancha", e se publicou este Libro Blanco de la economía Social de CastillaLa Mancha (454 páxinas, ISBN 978-84-09-25985-4), editado pola Universidade de Castilla-La Mancha. O Libro está dirixido polos profesores Felipe Hernández Perlines e Inmaculada Carrasco Monteagudo, sendo autores un equipo interdisciplinar de investigadores da Universidade de Castilla-La Mancha, integrado por: Miguel Ángel Alarcón Conde, Inmaculada Buendía Martínez, Beatriz Calderón Milán, María José Calderón Milán, Marcos Corchano Alcaraz, Inmaculada Ca- 
rrasco Monteagudo, Sebastián Castillo Valero, Felipe Hernández Perlines e José Antonio Prieto Juárez. Ademais, o Libro Blanco conta coa colaboración de 13 representantes das organizacións máis relevantes da Economía Social de CastillaLa Mancha.

O primeiro Libro Branco da economía social en España foi publicado en 1992 polo Ministerio do Traballo, sendo autores un equipo de investigadores do CIRIEC-España. A este Libros seguíronlle os publicados polas Comunidades Autónomas de Valencia, Galicia [(CANCELO, M. y BOTANA, M. (Dirs.), Libro branco da Economía Social en Galicia, CECOOP, Santiago de Compostela, 2018)], Aragón e, agora, Castilla-La Mancha. Este Libro Branco é un extraordinario estudo de investigación, no que se analiza con detalle a situación da economía social na rexión de Castilla-La Mancha, realizado seguindo a metodoloxía que, dende o CIRIEC-España, se ten empregado tamén nos Libros Brancos das Comunidades Autónomas citadas, polo que permite comparar a situación da economía social nesta rexión coa existente nas Comunidades de Valencia, Galicia e Aragón na data en que se teña realizado cada Libro Branco.

O Libro Branco permite obter unha radiografía precisa da situación da Economía Social de Castilla-La Mancha a 2020, consonte aos datos dispoñibles, non sempre completos e fiables. E é por iso que os autores se comprometen a que esta monografía sexa o punto de partida para a constitución dun "Observatorio de la Economía Social de Castilla-La Mancha", que permita darlle continuidade o traballo que conten este Libro Branco, ofrecendo datos máis precisos e completos do sector que axuden ás Administracións competentes e as entidades da economía social a adoptar as decisións mais eficaces para que as entidades da economía social sexan unha ferramenta importante de cohesión social e rexional, de desenrolo económico do medio rural e de participación cidadán.

Este Libro Branco se estrutura en tres partes, que son complementarias. A primeira parte está integrada polo capítulo 1 , e ten por obxecto, a modo de introdución ao estudio, deslindar dende un punto de vista xurídico o concepto de Economía Social. Así, baixo o título de "El marco jurídico de la economía social en Castilla-La Manca", José Antonio Prieto Juárez, Profesor Titular de Dereito do Traballo e da Seguridade Social da Universidade de Castilla-La Mancha, adoptando a metodoloxía proposta polo CIRIEC-España, agrupa o conxunto heteroxéneo de entidades que integran a Economía Social en Castilla-La Mancha en dous bloques: entidades de mercado e entidades de non mercado, para logo facer unha análise do réxime xurídico individualizado das entidades mais relevantes desde a perspectiva da súa inclusión na economía social, estudando tamén o reparto de competencias entre a Comunidade Autónoma e a Administración Xeral do Estado nesta materia. Máis con anterioridade, este autor tamén fai unha incursión histórica do concepto de economía social que, como é coñecido, en España rematou na positivización dun concepto legal no artigo 2 da Ley 5/2011, de 29 de marzo, de 
Economía Social: "Se denomina economía social al conjunto de las actividades económicas y empresariales, que en el ámbito privado llevan a cabo aquellas entidades que, de conformidad con los principios recogidos en el artículo 4, persiguen bien el interés colectivo de sus integrantes, bien el interés general económico o social, o ambos". Concepto legal que se complementa co catálogo aberto de empresas da economía social do artigo 5: "1. Forman parte de la economía social las cooperativas, las mutualidades, las fundaciones y las asociaciones que lleven a cabo actividad económica, las sociedades laborales, las empresas de inserción, los centros especiales de empleo, las cofradías de pescadores, las sociedades agrarias de transformación y las entidades singulares creadas por normas específicas que se rijan por los principios establecidos en el artículo anterior.

2. Asimismo, podrán formar parte de la economía social aquellas entidades que realicen actividad económica y empresarial, cuyas reglas de funcionamiento respondan a los principios enumerados en el artículo anterior, y que sean incluidas en el catálogo de entidades establecido en el artículo 6 de esta Ley".

\section{RADIOGRAFÍA DA ECONOMÍA SOCIAl DE CASTIlla-LA MANCHA}

Seguindo a metodoloxía do CIRIEC-España, a primeira categoría das empresas da económica social de mercado está integrada por aquelas entidades privadas creadas voluntariamente para satisfacer as necesidades dos socios, que producen bens e servizos para o mercado e obteñen a maioría dos seus recursos dos propios socios. Estamos a falar, pois, de operadores económicos que, en función da natureza da actividade de mercado que realizan, se subdividen en sociedades non financeiras (cooperativas, sociedades laborais, sociedades agrarias de transformación,...) e sociedades financeiras (cooperativas de crédito e seguros, mutuas de seguros, ...). Na categoría da "Economía Social de no mercado" se integran as entidades privadas que producen, coa colaboración de voluntarios, bens ou servizos que non están destinados á venta no mercado, senón que son ofertados gratuitamente ou a prezos non significativos aos fogares; entidades que, no caso de ter excedentes económicos non poden ser apropiados polos axentes fundadores, financiadores ou que as controlan.

Así delimitada a Economía Social, os estudos realizados no marco deste Libro Branco permiten coñecer e apreciar a importancia deste sector na rexión de Castilla-La Mancha. Así, dos datos contidos nas páxinas 437 a 442 do Libro Branco, a modo de resumo, podemos a seguinte radiografía. A Economía Social en Castilla-La Mancha agrupa a 6.821 entidades, que xeran 40.000 empregos, un valor engadido bruto (VAB) de 500 millóns de euros e integran a máis de 300.000 voluntarios.

No marco destas grandes cifras, as empresas da economía social de mercado agrupan a 3.642 entidades, que proporcionan 39.000 empregos e producen un 
VAB aproximado de 500 millóns de euros. Dentro desta categoría, as cooperativas son os principais produtores de mercado en Castilla-La Mancha, pois as 1.200 cooperativas existentes representan o $32 \%$ das entidades de mercado, dando emprego a 11.00 persoas (o $28 \%$ do emprego da economía social da rexión e o 1,7\% do emprego rexional), e sendo mais do $47 \%$ do VAB. O valor ou importancia destas cifras é aínda maior cando se aprecia que as cooperativas desta rexión se concentran no entorno rural de municipios escasamente poboados, polo que xogan un papel moi importante na fixación da poboación nunha rexión severamente afectada polo despoboamento. Baste dicir que case que o $30 \%$ das cooperativas están domiciliadas en concellos de menos de 2.000 habitantes, cando que a poboación que reside nestes concellos non chega ao $15 \%$. Así, pois as cooperativas en Castilla-La Mancha están a ser un potente motor económico en poboacións valeiras que frean o despoboamento e vertebran o territorio. En sentido negativo, esta realidade conduce ao minifundismo cooperativo e a baixa produtividade do traballo, o que redunda nunha menor competitividade.

As sociedades laborais da rexión alcanzaban a cifra de 700, cunha tendencia á baixa paralela a experimentada no resto do Estado, operando a maioría nos sectores de industrias extractivas e manufactureiras. Empregaron a 3.629 persoas no ano 2019, o que representa unha media de 5,2 traballadores, revelando unha notable atomización empresarial. Moito máis numerosas na rexión son as Sociedades Agrarias de Transformación (12.317), destacando o seu papel na modernización das explotacións agrarias de Castilla-La Mancha. Mucho menos numerosas son las "empresas socias" da economía social de mercado, subcategoría integrada polas empresas de inserción social e os centros especiais de emprego, presentes en actividades económicas pouco rendibles e caracterizadas polo feito de que a súa finalidade non é obter un lucro como satisfacer unha necesidade social en ámbitos como os servizos sociais, saúde, educación, cultura, etc. En 2019 había 8 empresas de inserción social que empregaban a 135 persoas, 67 delas en inserción laboral, en tanto que os centros especiais de empreso sumaban 90, xerando 4.102 postos de traballo.

No que fai as empresas de mercado financeiras, o Libro Branco reporta que existen en Castilla La-Macha (teñen sé na rexión e operan principalmente nela) 6 entidades, sendo 4 cooperativas de crédito, unha mutua de seguros de ámbito rexional e unha mutualidade de previsión social. Destácase no estudio a elevada ratio de solvencia das cooperativas de crédito, por encima do exixido polo regulador, así como o feito de que a maioría das cooperativas da rexión sexan socios dalgunha cooperativa de crédito, que no seu conxunto suman 15.000 millóns de euros en activos tendo proporcionado 9.000 millóns de euros en créditos.

As grandes cifras do bloque das entidades da economía social non lucrativa, ou entidades de non mercado, configuran un panorama mais modesto. Os autores do Libro Branco cifran en 3.390 as entidades non lucrativas, das que 2.864 teñen 
asalariados. Dentro dos distintos tipos de entidades que configuran esta categoría, as asociacións son a maioría (2.953), seguidas das fundacións (427), destacando entre elas tres entidades de ámbito nacional: Cáritas, Cruz Vermella e Fundación ONCE. Con todo, pese a que o VAB destes entidades non lucrativas non é elevado (44 millóns $€$ ), o volume de voluntarios que dedican parte do seu tempo a traballar nelas (31.260 persoas) permite aos autores estimar que esas entidades presentan, no seu conxunto, un excedente social de 345 millóns $€$.

\section{ESTRUTURA INTERNA DO LIBRO BRANCO}

O Capitulo 1 reseñado no anterior epígrafe integra a Parte Primeira do Libro Branco, que baixo o rótulo de "Ámbito, definición y escenario jurídico de la Economía Social en Castilla-La Mancha”, comprende as páxinas 23 a 89 do Libro Branco. Feito esta análise xurídica das entidades da economía social na Comunidade Autónoma, a Segunda leva por título "Las cifras de la Economía Social en Castilla-La Mancha”, e comprende 6 capítulos, nos que debuxa unha panorámica da importancia das distintas entidades da economía social na rexión. Os capítulos 2, 3 e 4 son obra as doutoras en economía Beatriz e María José Calderón-Milán. No capítulo 2 realizan un moi detallado estudo das cooperativas na rexión, comparando a súa situación respecto do total do Estado, concluíndo que a distribución das cooperativas de Castilla-La Mancha revela un papel fundamental na xeración de emprego e na fixación, promoción, desenrolo e mellora da poboación agraria e do medio rural, xa que tres cuartas partes do total de cooperativas ou ben son cooperativas de traballo asociado ou ben son cooperativas agrarias. Non obstante, poñen de relevo a necesidade de contar con información estatística mais precisa e actualizada, polo que propoñen a creación dun Observatorio de la Economía Social de Castilla-La Mancha como ferramenta útil para dar visibilidade ao sector, así como establecer acordos con distintas institucións que elaboren estatísticas para que incluían as diferentes formas organizativas das entidades da Economía Social como unha dimensión específica á hora de presentar os seus datos. O capítulo 3 contén un estudo de similar estrutura en relación coas sociedades laborais, que lles permite concluír que estas sociedades presentan unha elevada atomización e concentración en tres ramas de actividade: industrias extractivas e manufactureiras, comercio e hostalería e construción, volvendo a por de relevo a necesidade de contar con unha mellor e mais completa información estatística. Por último, o Capítulo 4 está dedicado ao estudo das sociedades agrarias de transformación, no se se conclúe que as SAT tamén presentan un elevado grao de atomización, maior incluso que a nivel do Estado, e que pese ao notable arraigo desta figura societaria na rexión, carecen dunha regulación propia rexional que adapte o seu réxime legal ás peculiaridades do territorio e do sector agrario da rexión, destacando as autoras que a case que total de información estatística desagregada ten impedido que se puidera estudar a súa evolución histórica. 
O Capítulo 5, de autoría dos profesores Felipe Hernández Perlines e Inmaculada Carrasco Monteagudo, ten por obxecto o estudo da situación das empresas do sector financeiro da economía social en Castilla-La Mancha. No Capítulo 6 a profesora Inmaculada Buendía-Martínez analiza a situación das empresas de inserción e dos centros especiais de emprego, concluíndo que a escasa dispoñibilidade de datos representa non permitiu realizar un estudo mais profundo da súa situación na rexión, que resulta imprescindible para validar a súa potencialidade económica e social, así como para deseñar planes estratéxicos. O Capítulo 7, que pecha esta Segunda Parte do Libro Branco, obra do profesor Miguel Ángel Alarcón Conde, ofrece as grandes cifras e unha primeira aproximación á conta de explotación produtiva e social das entidades do sector non lucrativo da economía social na rexión castelán manchega.

A Terceira Parte do Libro Branco, baixo o rótulo de "Otras aportaciones", acolle un total de trece colaboracións agrupadas nos capítulos 8 a 12. Os capítulos 8 a 10 acollen aportacións temáticas a cargo de profesores e investigadores da UCLM, en tanto que o Capítulo 11 agrupa aportacións realizadas por profesionais pertencentes a entidades concretas e representativas da economía social na rexión. E como xa mencionamos, o Capítulo 12 pecha o Libro Branco a modo de síntese e recapitulación. En particular, o Capítulo 8 leva por título "La revolución silenciosa de las cooperativas de vino en Castilla-La Mancha", sendo autor o profesor Juan Sebastián Castillo Valero, Director de Investigación da Sección de Economía Agroalimentaria e Desenrolo Rural do Instituto de Desenrolo Rexional da UCLM. O Capitulo 9 acolle un estudio sobre "El papel de la economía social en el desarrollo local y la fijación de la población de Castilla-La Mancha", a cargo del graduado en economía Marcos Carchano Alcaraz e da profesora en económica Inmaculada Carrasco Monteagudo. O capítulo 10 ten por título "Componentes de la economía social y sus fuentes. Referencia especial para el sector no lucrativo de Castilla-La Mancha". Indica o autor de este traballo, o profesor de economía da UCLM Miguel Ángel Alarcón Conde, que a finalidade de este capítulo é servir de base para o capítulo 7, xa que pretende contribuír aos fundamentos sobre a configuración dos compoñentes da economía social e particularmente do sector non lucrativo, así como ao coñecemento sobre as fontes dispoñibles para o seu estudo comparado para Castilla-La Mancha e España. Por último, o Capítulo 11 agrupa as aportacións realizadas polos profesionais de distintas entidades da economía social de Castilla-La Mancha. En concreto podemos atopar os traballos que seguen: Juan Miguel del Real Sánchez-Flor y Tomás Merino Rodríguez de Tembleque, "El cooperativismo agroalimentario como motor de la Economía Social de Castilla-La Mancha"; José Antonio Romero Manzanares y Marcelina de la Vega Ávila, "El Tercer Sector de acción social y la atención a las personas con discapacidad en Castilla-La Mancha"; Carlos Javier Hernández Yebra, "El Grupo Social Once en Castilla-La Mancha: entidad que suma, personas que multiplican"; 
Jesús Esteban Ortega, "Cruz Roja: cada vez más cerca de las personas"; Ángel Gómez García, "La Unión de Cooperativas de enseñanza de Castilla-La Mancha (UCECM)"; María Luisa Escudero Serrano, "Plena Inclusión Castilla-La Mancha": Justo Juan Pliego Romero, "El Cooperativismo de Trabajo Asociado en Castilla-La Mancha y surepresentación sectorial: UCTACAM"; Andrés Martínez Medina y Vicente Martínez Medina, "Modelos de innovación en la Economía Social. Grupo de entidades sociales CECAP, Toledo (España)"; Laura Arroyo Romero-Salazar y Luis Enrique Espinoza Guerra, "La Economía Solidaria en Castilla-La Mancha".

En definitiva, este Libro Branco é unha obra colectiva que ofrece unha completa radiografía da importancia cualitativa e cuantitativa da Economía Social en Castilla-La Mancha. Un traballo que completa e apoia a estratexia Integral para a Economía Social do Goberno rexional, e que pretende ser un punto de partida para a creación do Obervatorio da Economía Social de Castilla-La Mancha, que tería por obxecto recompilar, actualizar, xerar, difundir e analizar a información estatística existente, estreitar as vías de colaboración coa Universidade xa existentes, e serviría para apoiar a elaboración de políticas públicas de ámbito económico e social, como a toma de decisión para as entidades do sector. Neste sentido, chámase a atención sobre a deficiente información estatística existente e a necesidade de poder cruzar a información existente en diversos organismos rexionais e nacionais para obter un coñecemento mais profundo da situación do sector, necesaria para o deseño e implementación de políticas de fomento da economía social que responda aos retos actuais dunha economía sostible, verde e socialmente igualitaria. 